\title{
Cross-cultural adaptation, reliability and validity of the Spanish version of the upper limb functional index
}

\author{
Antonio I Cuesta-Vargas ${ }^{1,2^{*}}$ and Philip C Gabel ${ }^{3}$
}

\begin{abstract}
Background: The Upper Limb Functional Index (ULFI) is an internationally widely used outcome measure with robust, valid psychometric properties. The purpose of study is to develop and validate a ULFI Spanish-version (ULFI-Sp).

Methods: A two stage observational study was conducted. The ULFI was cross-culturally adapted to Spanish through double forward and backward translations, the psychometric properties were then validated. Participants ( $n=126$ ) with various upper limb conditions of $>12$ weeks duration completed the ULFI-Sp, QuickDASH and the Eurogol Health Questionnaire 5 Dimensions (EQ-5D-3 L). The full sample determined internal consistency, concurrent criterion validity, construct validity and factor structure; a subgroup $(n=35)$ determined reliability at seven days.

Results: The ULFI-Sp demonstrated high internal consistency $(a=0.94)$ and reliability $(r=0.93)$. Factor structure was one-dimensional and supported construct validity. Criterion validity with the EQ-5D-3 $L$ was fair and inversely correlated $(r=-0.59)$. The QuickDASH data was unavailable for analysis due to excessive missing responses.
\end{abstract}

Conclusions: The ULFI-Sp is a valid upper limb outcome measure with similar psychometric properties to the English language version.

Keywords: Upper limb, Psychometrics, Outcome measure, Spanish

\section{Introduction}

Health outcome assessment is an important component of patient care. Patient reported outcome (PRO) measures $[1,2]$ are primarily used to objectively reflect a patient's health or functional status at any given time and to detect changes in this status as a response to an intervention [3]. This assists the clinicians' understanding of the effects of a condition or disease on a patient's capabilities, functioning and symptoms [4]. Traditionally, clinical signs and symptoms were used as outcomes and studies that wished to reflect patient health status employed generic quality of life measures. However, over the last two decades region specific PROs that represent the three key body regions, of the upper limb, lower limb and spine have been used

\footnotetext{
* Correspondence: acuesta.var@gmail.com

'Department of Physiotherapy, Faculty of Health Science, University of Malaga, Malaga, Spain

${ }^{2}$ School of Clinical Science, Faculty of Health, Queensland University of Technology, Kelvin Grove, Australia

Full list of author information is available at the end of the article
}

more frequently in the assessment of a musculoskeletal patient's functional status [5]. The Upper Limb Functional Index (ULFI) is a recent example of this. It was initially published in a dichotomous format [6] then updated and modified to a three-point scale [7]. These regional PRO measures are argued to provide greater sensitivity and improved representation of the individual's functional status than joint or condition specific measures [7-9]. Though various region specific PROs have been used to assess upper-limb functional status, it is accepted that 'there is no gold standard [8,10-12]. These tools also guide treatment decisions and assess the effectiveness of interventions, including direct comparisons between pre- and post-operative status, and subsequently during rehabilitation [13].

There are several regional upper limb PROs that are advocated and recommended by national associations or organizations around the world for Physical, Occupational and Hand Therapy, Orthopedics and Surgery. This is 
through their respective institutional websites and subject related Journals. The Disability of Arm, Shoulder and Hand (DASH) [14-16] and the shortened QuickDASH [17] version are two prominent examples. However the DASH has [18] excessive internal consistency, with a documented Cronbach Alpha value $>0.95[6,8,12,19]$, the recognized upper limit for 'item redundancy' or the presence of too many items being too similar to enable a valid change to be detected [20]. The factor structure has also been challenged [21-23] which further questions validity. A questionnaire must provide a single-factor structure so that it can be summated to provide a single or summary score. It cannot be influenced by other constructs such as psychological or emotional status $[24,25]$. The QuickDASH, as derived from 11extracted DASH items, has also been challenged. The factor structure has not been consistently shown as one-dimensional [7,26-28], which raises concerns on its validity; and it has been found to underestimate symptoms and overestimate disability [29]. Several other regional PROs are also advocated. The Upper Extremity Functional Scale (UEFS) [30] which has been shown to lack reliability and methodological criteria [5,31]. The Upper Extremity Functional Index (UEFI) [32] which is criticized due to it development methodology using a specific workers population in a small data set with a high average age $[6,8]$. It has been subsequently independently validated [33] but uses a matrix response format which has a high error tendency for completion and scoring [34]. It is also reported to have no advantage over the DASH for measuring clinical change [35]. The Neck and Upper Limb Index (NULI) [36] which has been demonstrated as having item-redundancy from excessive internal consistency [8] and development concerns [37]. There are also a significant number of joint and condition specific scales but these cannot be used regionally as they do not consider the upper limb as a single kinetic chain $[8,18]$.

The ULFI with a three-point option improved both the responsiveness and practicality [7]. It was shown to have strong psychometric properties for reliability, validity, responsiveness, error measurement, and internal consistency that approximated or exceeded those of the DASH and UEFS [6]. The ULFI was shown to have strong psychometric properties for reliability, validity, responsiveness, error measurement, and internal consistency that approximated or exceeded those of the DASH and UEFS [6]. The ULFI's practical characteristics of brevity, ready transferability to a 100-point scale, ease and rapidity of completion and scoring reinforced the methodological consistency $[7,26,38]$. This comparative analysis in separate studies has provided scope to suggest the ULFI was preferred to the criterion tools of the DASH $[6,17,38]$, UEFS [6] and QuickDASH $[7,26]$ due to a combination of enhanced psychometric and practical characteristics. A further consideration was that the ULFI has a single factor structure [25] and an acceptable level of internal consistency in all studies.

The ULFI has also been accepted by the international PRO database [39] 'PROQUOLID'. A Spanish version of the ULFI had not been developed or validated to date. This is significant given that Spanish is one of the five most spoken languages and the second widest geographically [40]. Consequently, a Spanish version of the ULFI (ULFI-Sp) was developed to meet this need. The four published studies to date investigating the ULFI suggest the practical characteristics along with the responsiveness and error range $[4,8]$ ' are consistently defined $[6,7,26,38]$. Therefore the aims of this paper were: to describe the process of translation and cross-cultural adaptation of the original ULFI to Spanish; and to subsequently assess the four critical psychometric properties of reliability, factor structure, internal consistency, and concurrent criterion validity for clinical use with Spanish speakers.

\section{Materials and methods \\ Design}

A two stage observational study was conducted involving: initial translation and cross-cultural adaptation of the ULFI [7] to Spanish; then subsequent prospective concurrent completion with a general health questionnaire, the Euroqol Health Questionnaire 5 Dimensions (EQ-5D-3 L) [41] and an upper limb regional criterion, the QuickDASHSp [42]. A physical therapy outpatients' population was used for evaluation of the ULFI-Sp's four critical psychometric properties. TheEQ-5D-3 L was used to clarify the participants' health status and provide a criterion standard for health comparison. The QuickDASH-Sp was also completed by all participants but there were excessive levels of missing responses that unfortunately rendered the data not useable for analysis and reporting in this study. This may have been partially attributed to the QuickDASH being the final questionnaire in the completion sequence and subsequent patient burden due to the number of questionnaires. All questionnaires were completed and two assessors performed the initial and any subsequent assessments, but were blinded to baseline scores in order to ensure independent collection of outcome data.

\section{Translation of the ULFI to the "ULFI-Sp"}

The primary objective of this aspect of the study was to perform a translation that can ensure the conceptual equivalence of the used terms. Not only a direct and reverse translation methodology was applied, also a specialist in the field as detailed and recommended in the specialized scientific literature (Figure 1) [43,44]. 


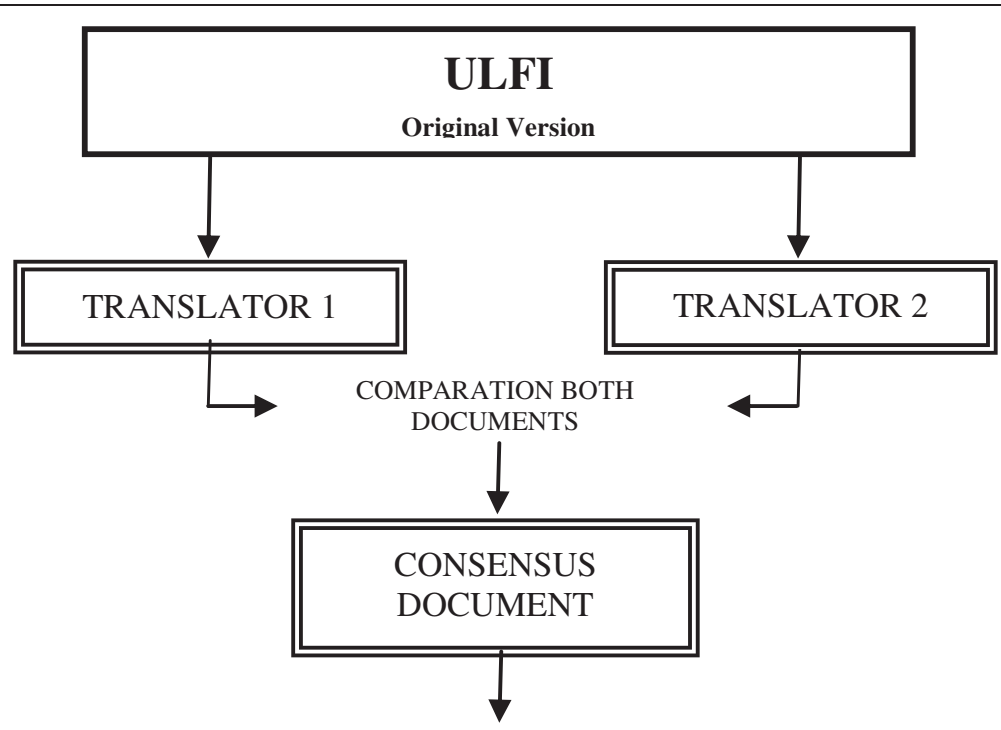

REVERSE TRANSLATION

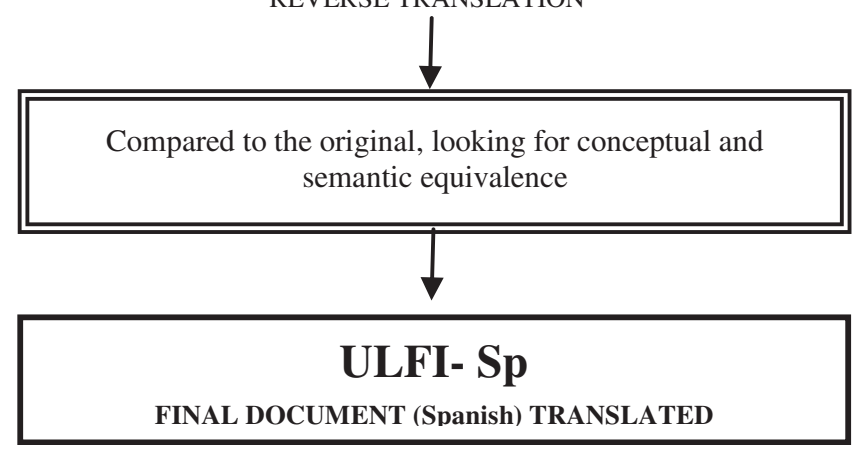

Figure 1 Flowchart of the translation of the Upper Limb Functional Index (ULFI) from English to Spanish.

\section{Participants, setting and procedure}

A total of 126 volunteers $(49 \pm 21$ years, $54.8 \%$ female) with a variety of upper limb conditions of $>12$ weeks duration were recruited consecutively from the Physical Therapy Clinic at the Malaga University. Written informed consent was obtained from the patient for the publication of this report. Inclusion criteria were an upper limb injury as diagnosed by the attending medical practitioner. Their presenting conditions and diagnoses were broadly classified into five categories (Table 1). The exclusion criteria were age $<18$ years and poor Spanish language comprehension as required for the completion of the questionnaires. All participants with eligible criteria completed the three Spanish language versions of the self-administered questionnaires, the ULFI-Sp, the EQ-5D-3 L and the QuickDASH-Sp.

The ULFI is a 25-item 3-point response option PRO that is scored by simple addition of the responses then converted to a 100 point percentage scale. Up to two missing responses are permitted [7]. The EQ-5D-3 L is a widely used six item non-disease-specific questionnaire. It has five 3-point response options for different quality-of- life dimensions and a sixth question on overall perceived health-related status. The EQ-5D-3 L-Visual Analogue Scale (VAS) is used to reflect the respondent's self-rated health status on a $100 \mathrm{~mm}$ scale and ranked from 'Best Imaginable' (100) to Worst Imaginable' (0). The EQ-5D-3 L has been demonstrated as valid and reliable in the Spanish population [42]. Reliability was performed using the Intraclass Correlation Coefficients Type 2,1 ( $\left.\mathrm{ICC}_{2.1}\right)$ test-retest methodology in a randomly selected subgroup of the full sample ( $n=35,46 \pm 62$ years, $61.1 \%$ female). Their presenting conditions were representative of the five categories of the full sample and expressed with a 95\% CI using scores on the ULFI-Sp from the participants at baseline and on repetition at day seven.

\section{Statistics}

Descriptive analyses were applied to calculate means and standard deviations of demographic variables (Table 1). Distribution and normality were determined by one-sample Kolmogorov-Smirnov tests (significance $>0.05$ ). Construct validity and factor structure were determined through the use of questionnaire principal component analysis (PCA) 
Table 1 Demographic characteristics and frequency of diagnosis of the study population

\begin{tabular}{|c|c|c|c|}
\hline \multirow[t]{2}{*}{ Characteristic } & \multirow[t]{2}{*}{ Cases } & Age (years) & \multirow[t]{2}{*}{$p$ value } \\
\hline & & Mean (sd) & \\
\hline Study Population & 126 & $49 \pm 21$ & \\
\hline Male & $57(45.2 \%)$ & $48 \pm 23.2$ & $0.02^{*}$ \\
\hline Female & $69(54.8 \%)$ & $51 \pm 24.1$ & \\
\hline \multicolumn{4}{|l|}{ Dominance } \\
\hline Right hand & 88 & $49 \pm 15.5$ & $0.00^{*}$ \\
\hline Left hand & 48 & $50 \pm 17.8$ & \\
\hline \multicolumn{4}{|l|}{ Injured at work } \\
\hline Yes & 51 & $45 \pm 15.5$ & $0.01^{*}$ \\
\hline No & 62 & $56 \pm 19.5$ & \\
\hline Unsure & 13 & $50 \pm 21.5$ & \\
\hline $\begin{array}{l}\text { Distribution of upper-limb } \\
\text { conditions }\end{array}$ & Area & Numbers & $\%$ \\
\hline Impingement Syndrome & Shoulder & 39 & $31 \%$ \\
\hline Shoulder Tendinitis/osis & Shoulder & 32 & $25 \%$ \\
\hline Wrist fracture & Hand & 30 & $24.5 \%$ \\
\hline Arm fracture & Arm & 13 & $10 \%$ \\
\hline Carpal Tunnel Syndrome & Hand & 12 & $9.5 \%$ \\
\hline
\end{tabular}

* Indicates Significance.

with the a-priori requirements for extraction being the satisfaction of all three points: screeplot inflection point, Eigenvalue $>1.0$ and accounting for $>10 \%$ of variance. We satisfied the recommended minimum ratio of five participants-per-item [24]. Internal consistency of the scale items was determined from Cronbach's $\alpha$ coefficients as calculated at an anticipated value range of 0.80-0.95 $[20,45]$. Student's t-test will be developed to check the items behave the same way for men and women.

An external validation scale of the EQ-5D-3 L and EQ-5D-3 L-VAS was used with bilateral correlations to establish if status had changed and an error range of $0 \pm 10 \%$ was allowed in determining the test-retest reliability.

The $M D C_{90}$ analysis was performed as described by Stratford [32]. The standard error of the measurement (SEM) was calculated using the formula: $\operatorname{SEM}=s \sqrt{ }(1-r)$, where $\mathrm{s}=$ the mean and standard deviation (SD) of time 1 and time 2, r = the reliability coefficient for the test and Pearson's correlation coefficient between test and retest values. Thereafter the $\mathrm{MDC}_{90}$ was calculated using the formula: $\mathrm{MDC}_{90}=\mathrm{SEM} \times \sqrt{2} \times 1.96$.

Criterion validity was determined through the concurrent use of the EQ-5D-3 L total score and EQ-5D-3 L-VAS scores with the ULFI-Sp measures. The QuickDASH was unavailable due to excessive completion errors. The Pearson's $r$ correlation coefficient used the criteria of poor $(r<0.49)$, fair $(r=0.50-0.74)$ and strong $(r>0.75)$ [46].
Sample size was determined from the previous ULFI studies [7,8,26] indicating a minimum of 106 patients were required to ensure an $80 \%$ chance of achieving the required statiscal power for concurrent validity, internal consistency and factor structure allowing for 15\% attrition $(p<0.05)$ [46]. For reliability a minimum of $\mathrm{n}=29$ was required.

All statistical analyses were conducted using the Statistical Package for Social Science version 17.0 (SPSS 17.0) for Windows and LISREL 8.80 [47].

Ethical clearance was approved by the Tribunal of Review of Human Subjects at the University of Malaga.

\section{Results}

\section{Characteristic descriptive of the participants}

The demographic and frequency of diagnosis of the study sample are detailed in Table 1 . The ULFI was translated and back translated with consideration of the Spanish cultural linguistic adaptation to provide the new ULFI-Sp questionnaire without language difficulties or other conceptual misunderstanding. (Additional file 1). The normative values from ULFI-Sp score were mean and standard deviation of $5.88 \pm 5.6$ points. The ULFI-Sp showed no missing responses and showed a high degree of internal consistency, as illustrated by the high Cronbach value $(\alpha=0.94)$ with an individual item range of 0.92 to 0.96 . The test-retest reliability was high at $(r=0.93)$ with an individual range of 0.92 to 0.95 . The total score was accounted for, not the individual questionnaire response items. Measurement error was determined from SEM and $\mathrm{MDC}_{90}$ being respectively at $3.52 \%$ and $8.03 \%$. No significance differences were found between gender in the item responses.

The correlation matrix for the ULFI-Sp was determined suitable from the Kaiser-Meyer-Oklin values (0.89) and Barlett's Test of Sphericity $(\mathrm{p}<0.001)$. This indicated that the correlation matrix was unlikely to be an identity matrix and was therefore suitable for PCA. The screeplot (see Figure 2) indicated a one-factor solution. The factor analysis revealed a satisfactory percentage of total variance explained by the one factor at $48.9 \%$. It was noted that four factors had Eigenvalues $>1.0$ and accounted for $85.8 \%$ of variance; however those with an Eigenvalue $>1.0$ each accounted for $<10 \%$ of variance and were shown to be after the screeplot initial inflection point (Figure 2) and consequently not extracted. The item loading for the one-factor solution for the PCA method and average score for each item is shown in Table 2.

Criterion validity determined from the relationship between the ULFI-Sp and EQ-5D-3 L $(r=-0.59)$ and EQ-5D-3 L-VAS $(\mathrm{r}=-0.51)$ indicated a fair and inverse correlation. The QuickDASH-Sp had greater than $>30 \%$ of missing responses affecting 41 of the 126 respondent 


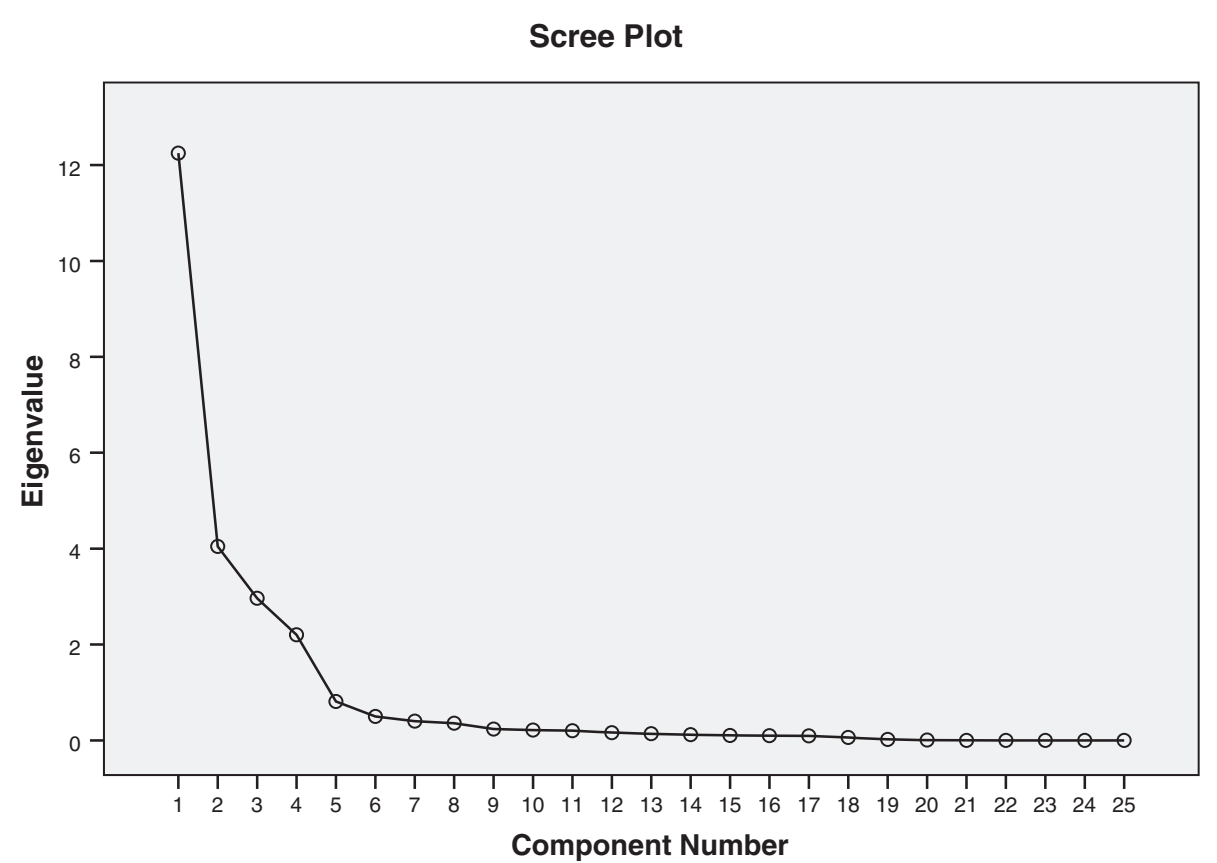

Figure 2 Scree Plot of the exploratory one-factor solution.

questionnaires. This rendered invalid any reporting of criterion validity or factor structure with this tool.

\section{Discussion}

\section{Main findings}

The ULFI was translated to provide a cross-cultural adaptation to the Spanish language. The translation process ensured the conceptual equivalence of the used terms. This provided accessibility to the ULFI for the second largest geographically used language. The psychometric properties, specifically construct and criterion validity, reliability and internal consistency were determined independently and found to be strong and the single factor structure indicated that a single summated score could be used [25].

The cross-cultural adaptation of the ULFI into Spanish enables clinicians in Spanish speaking settings to compare outcomes following their treatments and interventions affecting the upper limb. The procedure of cross-cultural adaptation of a scale has been used in previous studies for different scales to be applied in the Spanish context $[43,44]^{-}$The ULFI was translated into Spanish with no difficulty and the process complied with these standardized procedures. It is critical to employ research measures that are valid and reliable but they must also be both culturally and linguistically appropriate.

The one-factor solution that emerged in the factor analysis accounted for a significant proportion of variance and showed evidence that supports the presence of construct validity. A one-factor solution is critical if a
PRO is to be used with a single summated score and subsequently reflect the construct for which it is primary used - that of representation of the functional status of the upper limb as a single kinetic chain $[25,48]$. Any study using confirmatory factor analysis would be advantageous.

Two of the three other critical psychometric properties of the ULFI-Sp were both shown to be high and well supported. Internal consistency analysis showed a level of 0.94 that sits below the accepted 0.95 thresholds for item reducndancy [20]. This notably high level, when taken in context with the presence of the factor structure item loading Eigenvalues above 1.0, would indicate the potential for a shortened version of this tool. This supports the findings of the previous research where redundancy was not present but potential shortening was recommended, perhaps to as low as 10 items [7]. The test-retest reliability or reproducibility was also high with the values $(0.92$ to 0.95$)$ in-line with those found for the original instrument (0.90 to 0.96) [8].

The criterion validity demonstrated only a fair degree of differential association with the EQ-5D-3 L and EQ5D-3 L-VAS. This is considered to support the criterion validity of the ULFI-Sp however as it is not as strong as findings in the previous research that used a region specific criterion standard that was advocated as representative of the upper limb kinetic chain. The QuickDASH criterion was not available for criterion comparison due to the excessive number of missing responses. This may have been partially attributed to patient burden as the QuickDASH was the final questionnaire completed. 
Table 2 Factor loading items for the one-factor solution, average score and discrimination indices of items

\begin{tabular}{|c|c|c|c|c|}
\hline Question & Item & Factor loading & Item average score & Item discr indices \\
\hline 1 & Stay at home most of time & .725 & .30 & $.666^{* *}$ \\
\hline 2 & Change positions frequently & .842 & .44 & $.824^{* *}$ \\
\hline 3 & Avoid heavy jobs & .730 & .25 & $.670^{* *}$ \\
\hline 4 & Rest more often & .914 & .17 & $.886^{* *}$ \\
\hline 5 & Get others to do things & .914 & .12 & $.886^{* *}$ \\
\hline 6 & Pain almost all the time & .876 & .15 & $.850^{* *}$ \\
\hline 7 & Lifting and carrying & .672 & .10 & $.631^{* *}$ \\
\hline 8 & Appetite affected & .344 & .20 & $.434^{* *}$ \\
\hline 9 & Walking/normal recreation/sport & .599 & .25 & $.672^{* *}$ \\
\hline 10 & Home/family duties and chores & .570 & .19 & $.675^{* *}$ \\
\hline 11 & Sleep less well & .296 & .13 & $.283^{* *}$ \\
\hline 12 & Assistance with personal care, hygiene & .511 & 25 & $.576^{* *}$ \\
\hline 13 & Regular daily activity work/social & .762 & .27 & $.777^{* *}$ \\
\hline 14 & More irritable/bad tempered & .344 & .18 & $.466^{* *}$ \\
\hline 15 & Feel weaker or stiffer & .825 & .38 & $.762^{* *}$ \\
\hline 16 & Transport independence & .511 & .29 & $.576^{* *}$ \\
\hline 17 & Arm in shirt sleeve/dressing & .888 & .20 & $.860^{* *}$ \\
\hline 18 & Writing/using keyboard or mouse & .511 & .17 & $.576^{* *}$ \\
\hline 19 & Do things at/above shoulder & .295 & .10 & $.209^{*}$ \\
\hline 20 & Eating: using utensils & .929 & .12 & $.898^{* *}$ \\
\hline 21 & Hold or moving dense objects & .891 & .18 & $.868^{* *}$ \\
\hline 22 & Drop things-minor accidents & .909 & .18 & $.883^{* *}$ \\
\hline 23 & Use other arm more often & .675 & .33 & $.614^{* *}$ \\
\hline 24 & Difficult button key coins taps & .825 & .52 & $.762^{* *}$ \\
\hline 25 & Open, hold, press, or push & .206 & .43 & $.303^{* *}$ \\
\hline
\end{tabular}

** Indicates Significance $<0.01$.

Consequently, this study shows that the ULFI-Sp will be of value in the assessments of patients with upper limb disorders in clinical and research settings.

\section{Study strengths and weaknesses}

The strengths of the study include the prospective nature adequate number of subjects, the inclusion of consecutive patients and the limited selection bias [24,32]. The results for the psychometric properties support the findings of the previous research on the original English version of the ULFI indicating broad cross-cultural adaptions would be appropriate to other diverse cultural and linguistic groups. The ULFI-Sp also provides a means of comparing upper limb health state in Spanish-speaking patients with their English-speaking counterparts in countries with a high Spanish population such as the United States.

The study limitations include the lack of longitudinal data regarding other psychometric properties including responsiveness or sensitivity to change and error scores as a representation of a minimal clinically important difference. The determination of construct validity through the use of factor analysis represents only one possible statistical method of testing. A construct is not restricted to one set of observable indicators or attributes and additional indicators will need to be considered in future research. Similarly, the practical characteristics were not determined. The inability to use the QuickDASH-Sp data collected in the clinical setting due to excessive missing responses, potentially from patient burden due to being the final questionnaire, resulted in no direct comparison with a regional upper limb criterion, a requirement for future studies. Patient burden from completing numerous questionnaires is an area for future consideration. A potential source of bias was that the scales were provided always in the same order. Finally, the inclusion of Hispanic/Latino/ South American participants in future studies could potentially provide confirming or conflicting linguistic information due to the cultural and ethnic difference with respect to the Spanish participants. 


\section{Conclusions}

The psychometric properties of the Spanish version of the ULFI are reported here for the first time. The determined values were satisfactory and supportive of the findings of the ULFI as a 3-point scale, particularly in the areas of internal consistency, factor structure and reliability. Consequently, the ULFI-Sp may be useful in Spanishspeaking populations and for making cross-ethnic and cross-cultural comparisons in other English speaking countries with a high Spanish-speaking population.

\section{Additional file}

\section{Additional file 1: The Spanish Version of the ULFI.}

\section{Competing interests}

The authors declare they have no competing interests.

\section{Authors' contributions}

All the authors have made contributions to conception of this study. Antonio I. Cuesta-Vargas and Phillip C Gabel participated in the analysis and interpretation of data and were involved in drafting the manuscript or revising it critically for important intellectual content. All the authors have given final approval of the version to be published.

\section{Acknowledgments}

The authors are grateful to the volunteers for their participation and the PMDT, Malaga. This study received a grant from the Research Office of the University of Malaga.

\section{Author details}

'Department of Physiotherapy, Faculty of Health Science, University of Malaga, Malaga, Spain. ${ }^{2}$ School of Clinical Science, Faculty of Health, Queensland University of Technology, Kelvin Grove, Australia. ${ }^{3}$ Centre for Healthy Activities, Sport and Exercise, Faculty of Science, University of the Sunshine Coast Queensland, Sippy Downs, Australia.

Received: 19 April 2013 Accepted: 25 July 2013

Published: 26 July 2013

\section{References}

1. Garratt A: Patient reported outcome measures in trials, Editorial. BMJ 2009, 338:2597.

2. Cella D, Yount S, Rothrock N, Gershon R, Cook K, Reeve B, Ader D, Fries JF, Bruce B, Rose M: PROMIS Cooperative Group. The Patient-Reported Outcomes Measurement Information System (PROMIS): Progress of an NIH Roadmap Cooperative Group During its First Two Years. Med Care, 45(5):S3-S11.

3. Fayers PM, Machin D, et al: Quality of Life: Assessment, Analysis and Interpretation of Patient-reported Outcomes. Wiley: Chichester; 2000.

4. Morris LA, Miller DW: The regulation of Patient-Reported Outcome claims: need for a flexible standard. Value Health 2002, 5:372-381.

5. McPhail SM, Bagraith KS, Schippers M, Wells PJ, Hatton A: Use of Condition Specific Patient-Reported Outcome Measures in Clinical Trials among Patients with Wrist Osteoarthritis: A Systematic Review. Adv Orthop 2012, 273421:10.

6. Gabel CP, Michener LA, Burkett B, Neller A: The Upper Limb Functional Index: Development and Determination of Reliability, Validity, and Responsiveness. J Hand Ther 2006, 19(3):328-349.

7. Gabel CP, Michener LA, Melloh M, Burkett B: Modification of the Upper Limb Functional Index to a Three-point Response Improves Clinimetric Properties. J Hand Ther 2010, 23(1):41-52

8. Michener LA, Leggins BG: A review of self-report scales for the assessment of functional limitation and disability of the shoulder. J Hand Ther 2001, 14(2):68-76.
9. Mintken PE, Glynn P, Cleland JA: Psychometric properties of the shortene disabilities of the Arm, Shoulder, and Hand Questionnaire (QuickDASH) and Numeric Pain Rating Scale in patients with shoulder pain. J Shoulder Elbow Surg 2009, 18(6):920-926.

10. Miller LA, Swanson S: Summary and Recommendations of the Academy's State of the Science Conference on Upper Limb Prosthetic Outcome Measures. J Prosthet Orthot 2009, 21:83-89.

11. Fayad F, Mace Y, Lefevre-Colau MM, Poiraudeau S, Rannou F, Revel M: Measurement of shoulder disability in the athlete: a systematic review [In French]. Ann Readapt Med Phys 2004, 47(6):389-395.

12. Schoneveld K, Wittink H, Takken T: Clinimetric evaluation of measurement tools used in hand therapy to assess activity and participation. $J$ Hand Ther 2009, 22(3):221-236.

13. Patel AA, Donegan D, Albert T: The 36-item short form. J Am Acad Orthop Surg 2007, 15(2):126-134.

14. Smith MV, Calfee RP, Baumgarten KM, Brophy RH, Wright RWJ: Upper extremity-specific measures of disability and outcomes in orthopaedic surgery. Bone Joint Surg Am 2012, 94(3):277-285

15. Germann G, Harth A, Wind G, Demir E: Standardisation and validation of the German version 2.0 of the Disability of Arm, Shoulder, Hand (DASH) questionnaire (in German). Unfallchirurg 2003, 106(13):19.

16. Greenslade JR, Mehta RL, Belward P, Warwick DJ: DASH and Boston Questionnaire assessment of carpal tunnel syndrome outcome: what is the responsiveness of an outcome questionnaire? J Hand Surg 2004 29(2):159-164

17. Beaton DE, Wright JG, Katz JN, Group UEC: Development of the QuickDASH: comparison of three item-reduction approaches. J Bone Joint Surg Am 2005, 87(5):1038-1046.

18. Beaton DE, Katz JN, Fossel AH, Wright JG, Tarasuk V, Bombardier C: Measuring the whole or the parts? Validity, reliability, and responsiveness of the Disabilities of the Arm, Shoulder and Hand outcome measure in different regions of the upper extremity. $J$ Hand Ther 2001, 14(2):128-146.

19. Van de Ven-Stevens LA, Munneke M, Terwee CB, Spauwen PH, van der Linde $\mathrm{H}$ : Clinimetric properties of instruments to assess activities in patients with hand injury: a systematic review of the literature. Arch Phys Med Rehabil 2009, 90(1):151-169.

20. Terwee CB, Bot SD, de Boer MR, van der Windt DA, Knol DL, Dekker J, Bouter LM, de Vet HC: Quality criteria were proposed for measurement properties of health status questionnaires. J Clin Epidemiol 2007, 60:34-42.

21. Lehman LA, Woodbury M, Velozo CA: Examination of the factor structure of the Disabilities of the Arm, Shoulder, and Hand questionnaire. Am J Occup Ther 2011, 65(2):169-178.

22. Franchignoni F, Giordano A, Sartorio F, Vercelli S, Pascariello B, Ferriero G: Suggestions for refinement of the Disabilities of the Arm, Shoulder and Hand Outcome Measure (DASH): a factor analysis and Rasch validation study. Arch Phys Med Rehabil 2010, 91(9):1370-1377.

23. Angst F, Schwyzer HK, Aeschlimann A, Simmen BR, Goldhahn J: Measures of adult shoulder function: Disabilities of the Arm, Shoulder, and Hand Questionnaire (DASH) and its short version (QuickDASH), Shoulder Pain and Disability Index (SPADI), American Shoulder and Elbow Surgeons (ASES) Society standardized shoulder assessment form, Constant (Murley) Score (CS), Simple Shoulder Test (SST), Oxford Shoulder Score (OSS), Shoulder Disability Questionnaire (SDQ), and Western Ontario Shoulder Instability Index (WOSI). Arthritis Care Res (Hoboken) 2011, 11(63):174-188.

24. Kass RA, Tinsley HEA: Factor analysis. J Leisure Res 1979, 11:120-138.

25. Doward LC, McKenna SP: Defining Patient-Reported Outcomes. Value Health 2004, 7:4-8

26. Gabel CP, Yelland M, Melloh M, Burkett B: A modified QuickDASH-9 provides a valid outcome instrument for upper limb function. BMC Musculoskelet Disord 2010, 10:161

27. Fayad F, Lefevre-Colau MM, Gautheron V, Macé Y, Fermanian J, Mayoux Benhamou A, Roren A, Rannou F, Roby-Brami A, Revel M, Poiraudeau S: Reliability, validity and responsiveness of the French version of the questionnaire Quick Disability of the Arm, Shoulder and Hand in shoulder disorders. Man Ther 2009, 14(2):206-212.

28. Franchignoni F, Ferriero G, Giordano A, Sartorio F, Vercelli S, Brigatti E: Psychometric properties of QuickDASH - A classical test theory and Rasch analysis study. Man Ther 2011, 16(2):177-182. 
29. Angst F, Goldhahn J, Angst F, Goldhahn J, Drerup S, Flury M, Schwyzer HK, Simmen BR: How sharp is the short QuickDASH? A refined content and validity analysis of the short form of the disabilities of the shoulder, arm and hand questionnaire in the strata of symptoms and function and specific joint conditions. Qual Life Res 2009, 18(8):1043-1051.

30. Pransky G, Feuerstein M, Himmelstein J, Katz JN, Vickers-Lahti M: Measuring functional outcomes in work-related upper extremity disorders. Development and validation of the Upper Extremity Function Scale. J Occup Environ Med 1997, 39(12):1195-1202.

31. Sambandam SN, Priyanka PAG, llango B: Critical analysis of outcome measures used in the assessment of carpal tunnel syndrome. Int Orthop 2008, 32(4):497-504.

32. Stratford PW: Getting more from the Literature: estimating the standard error of measurement from reliability studies. Physiother Can 2004, 56:27-30.

33. Heffor C, Abbott JH, Heffor C, Abbott: The Patient-Specific Functional Scale: Validity, Reliability, and Responsiveness in Patients With Upper Extremity Musculoskeletal Problems. J Orthop Sports Phys Ther 2012, 42(2):56-65.

34. Gabel CP, Melloh M, Burkett B, Michener L: The Lower Limb Functional Index: development and validation of the clinimetric properties and practical characteristics. Phys Ther 2012, 92(1):98-110.

35. Lehman LA, Sindhu BS, Shechtman O, Romero S, Velozo CA: A comparison of the abiity of two upper extremity assessments to measure change in function. J Hand Ther 2010, 23(1):31-39.

36. Stock SR, Streiner D: The impact of neck and upper limb musculoskeletal disorders on the lives of affected workers: development of a new functional status index. Qual Life Res 1995, 4:491.

37. Salerno DF, Copley-Merriman C, Taylor TN, Shinogle J, Schulz RM: A review of functional status measures for workers with upper extremity disorders. Occup Environ Med 2002, 59(10):664-670.

38. Dale LM, Strain-Riggs SR: Comparing responsiveness of the Quick Disabilities of the Arm, Shoulder, and Hand and the Upper Limb Functional Index. Work 2012 [Epub ahead of print].

39. PROQoLD website. http://www.proqolid.org/instruments/ upper_limb_functional_index_ulfi?fromSearch=yes\&text=yes.

40. ONU: Paises de habla hispana promueven uso del español en la ONU. http://Www. un.org/spanish/News/fullstorynews.asp?news ID = 6370\&criteria1 = cultura.

41. Badía X, Roset M, Montserrat S, Herdman M, Segura A: The Spanish version of EuroQoL: A description and its applications. European Quality of Life scale. Med Clin (Barc) 1999, 112:79-85.

42. Hervás MT, Navarro Collado MJ, Peiró S, Rodrigo Pérez JL, López Matéu P, Martínez Tello I: panish version of the DASH questionnaire. Cross-cultural adaptation, reliability, validity and responsiveness [Article in Spanish]. Med Clin (Barc) 2006, 127(12):441-447.

43. Cuesta-Vargas A, Gonzalez-Sanchez M, Farasyn A: Development of a Spanish version of the "Backache Index" Cross cultural linguistic adaptation and reliability. J Back Musculoskelet Rehabil 2010, 23:105-110.

44. Muñiz J, Elosua P, Hambleton RK: International Test Commission Guidelines for test translation and adaptation: Second edition. Psicothema 2013, 25:151-157.

45. Cronbach $\sqcup$ : Coefficient alpha and the internal structure of tests. Psychometrika 1951, 16:297-334.

46. Field A: Discovering Statistics using SPSS. London: SAGE Publications Ltd; 2005.

47. Jöreskog KG, Sörbom D: LISREL 8.80. Chicago: Scientific Software International; 2007.

48. Alderman AK, Chung KC: Measuring Outcomes in Hand Surgery. Clin in Plastic Surg 2008, 35:239-250

doi:10.1186/1477-7525-11-126

Cite this article as: Cuesta-Vargas and Gabel: Cross-cultural adaptation, reliability and validity of the Spanish version of the upper limb functional index. Health and Quality of Life Outcomes 2013 11:126.

\section{Submit your next manuscript to BioMed Central and take full advantage of:}

- Convenient online submission

- Thorough peer review

- No space constraints or color figure charges

- Immediate publication on acceptance

- Inclusion in PubMed, CAS, Scopus and Google Scholar

- Research which is freely available for redistribution

Submit your manuscript at www.biomedcentral.com/submit 